\title{
Model Predictive Voltage Control with Optimal Duty Cycle for Three-Phase Grid-Connected Inverter
}

\author{
Shahrouz Ebrahimpanah $\mathbb{D}$, Qihong Chen $\mathbb{D}^{\mathbb{D}}$, Liyan Zhang $\mathbb{D}$, and Misbawu Adam $(\mathbb{D})$ \\ School of Automation, Wuhan University of Technology, Wuhan 430070, China \\ Correspondence should be addressed to Qihong Chen; chenqh@whut.edu.cn
}

Received 22 January 2019; Revised 13 April 2019; Accepted 22 April 2019; Published 12 May 2019

Academic Editor: Carlos-Andrés García

Copyright (c) 2019 Shahrouz Ebrahimpanah et al. This is an open access article distributed under the Creative Commons Attribution License, which permits unrestricted use, distribution, and reproduction in any medium, provided the original work is properly cited.

This paper proposes a model predictive voltage control (MPVC) strategy with duty cycle control for grid-connected three-phase inverters with output LCL filter. The model of the system is used to predict the capacitor filter voltage according to the future output current for each possible switching state at each sampling period. Then the cost function for each prediction is determined and the switching state is selected. In the proposed method, two voltage vectors are applied during one sampling interval to achieve better steady-state performance. Finally, the optimal duration of the nonzero voltage vector is defined based on the duty cycle optimization, which is vital to the control system. The proposed strategy offers a better reference tracking error with less THD in linear and nonlinear load situations. The effectiveness of the proposed method has been verified by MATLAB/Simulink and experimental results exhibit a better steady-state performance with less sampling frequency.

\section{Introduction}

Renewable energy generation systems, such as photovoltaic and wind turbine connected to power grid are drawing more and more attention in recent years. The grid-connected inverters play an important role in the distributed generation systems $[1,2]$. For this reasons, inverter control plays a significant role in the performance of the grid-tied inverters system. Therefore selecting a better power converter and better control method can lead to efficient system operation and better performance with less total harmonic distortions to achieve better grid current quality $[3,4]$. Three-phase inverter with output LCL filter connected to the grid is one of the most popular applications in the power systems to transfer DC voltage source to a symmetrical three-phase AC sinusoidal voltage. Thus, it can supply symmetrical sinusoidal voltages to the consumers in the standalone power systems without using of a magnetic transformer [5].

The applications with LC or LCL filter: the output voltage is selected to regulate the inverter, while the output current is chosen for inverter control in L-filter based applications. For controlling voltage, many classical control techniques such as linear proportional integral derivative (PID) controllers, hysteresis regulators based on pulse width modulation (PWM), variable structure control, open-loop feed forward controllers, pole placement controllers, and sliding mode control have been previously studied. Most of these complex control methods require $3 \mathrm{D}$-space vector modulation $[6,7]$, which is quite complex in nature, time consuming, and complicated software and digital implementation. But recently the finite control set model predictive control (FCS-MPC) has been found as a new control scheme in power electronics and drives systems [5]. This method has been applied in wide range of power converters applications compared to the classical control methods at lower switching frequency operation. This is due to its simple nature, fast dynamic response, and nonlinearities in the control design. Thus during such conditions the FCS-MPC strategy provides better steadystate performance $[8,9]$. However, the conventional finite control set model predictive voltage control (FCS-MPVC) employs one voltage vector during one sampling period and optimization of duty cycle is not involved in the control method; therefore, it needs a high sampling frequency to achieve a better performance. Due to these reasons, research on new strategies to obtain better steady-state performance in lower sampling frequency is important [10-13].

This paper presents a new proposed method (MPVC with duty cycle optimization) to control the grid-connected 


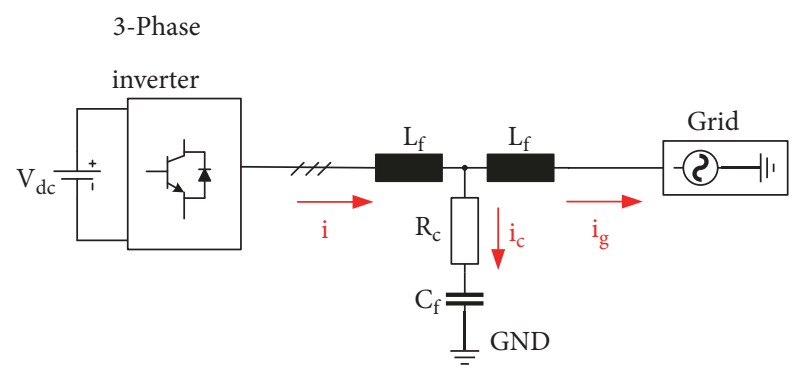

Figure 1: Block diagram of a two-level three-phase inverter with output LCL filter connected to the grid.

three-phase inverter with output LCL filter. In this proposed strategy, predictive voltage is determined by predicted output current, which means there are two prediction steps, first output current prediction and then voltage prediction. It can compensate for the effects of uncertainties in the load. Therefore, it is suitable for any type of load such as balanced, unbalanced, and nonlinear loads. In addition, it has better dynamic response. However, in the conventional strategy output voltage is predicted directly, which needs high sampling time to get better performance. From the other point of view, the proposed method uses a nonzero voltage vector and a zero voltage vector during one sampling period. Then, the duration of the nonzero and zero voltage vectors are determined according to the duty cycle optimization, which is key in the control system to avoid any effects on the dynamic response and obtain better steady-state performance at lower sampling time [14-18]. This paper is organized as follows: Section 2 introduces inverter analysis. Principle of MPVC is surveyed in Section 3. Then, Section 4 presents simulation and experimental results. Finally, conclusions are summed up in Section 5.

\section{Inverter Analysis}

This paper connected the three-phase inverter with output LCL filter to the grid which is shown in Figure 1.

The switching state of 6 power switches is represented by gating signals $S_{a}, S_{b}$, and $S_{c}$ found as follows [18]:

$$
\begin{aligned}
& S_{a}= \begin{cases}1 & \text { if } S_{1} \text { on and } S_{4} \text { off } \\
0 & \text { if } S_{1} \text { off } \text { and } S_{4} \text { on }\end{cases} \\
& S_{b}= \begin{cases}1 & \text { if } S_{2} \text { on } \text { and } S_{5} \text { off } \\
0 & \text { if } S_{2} \text { off } \text { and } S_{5} \text { on }\end{cases} \\
& S_{c}= \begin{cases}1 & \text { if } S_{3} \text { on } \text { and } S_{6} \text { off } \\
0 & \text { if } S_{3} \text { off } \text { and } S_{6} \text { on }\end{cases}
\end{aligned}
$$

And the switching state vector can be determined in vectorial form

$$
S=\frac{2}{3}\left(S_{a}+a S_{b}+a^{2} S_{c}\right)
$$

where $a=e^{j(2 \Pi / 3)}=-(1 / 2)+j(\sqrt{3} / 2)$.

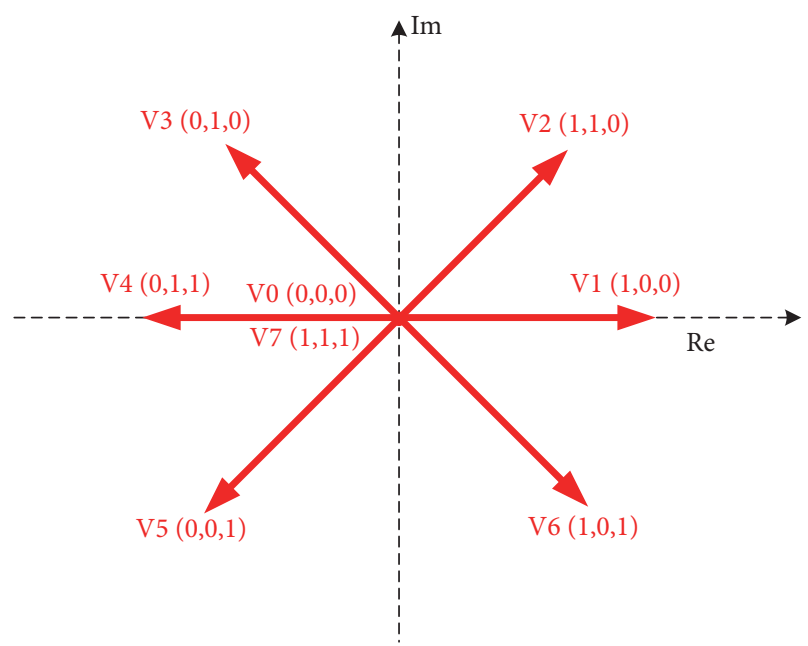

Figure 2: Possible voltage vectors generated by the inverter.

The output voltage space vectors are expressed by

$$
V=\frac{2}{3}\left(V_{a N}+a V_{b N}+a^{2} V_{c N}\right)
$$

where $V_{a N}, V_{b N}$, and $V_{c N}$ are the phase-to-neutral $(\mathrm{N})$ voltages of the inverter, where $\mathrm{N}$ is the negative terminal of the DC-link. Therefore, output voltage vector $\mathrm{V}$ can be express based on the switching state vector $\mathrm{S}$ and $\mathrm{dc}$-link voltage as the following:

$$
V=V_{d c} S
$$

where $V_{d c}$ is the DC source voltage.

According to Figure 2, there are seven different possible combinations of the switching states [18].

Using the vectorial format, the output current $i$, the capacitor filter voltage $V_{c}$, and the grid current $i_{g}$ can be expressed as space vectors and are expressed as

$$
\begin{aligned}
i & =\frac{2}{3}\left(i_{a}+a i_{b}+a^{2} i_{c}\right) \\
V_{c} & =\frac{2}{3}\left(V_{c a}+a V_{c b}+a^{2} V_{c c}\right) \\
i_{g} & =\frac{2}{3}\left(i_{g a}+a i_{g b}+a^{2} i_{g c}\right)
\end{aligned}
$$

As shown in Figure 1, the LCL filter is modelled in the block diagram. This model can be expressed by two equations of inductance dynamics and the capacitor dynamics [19].

The dynamic behaviour of the output current can be defined by the following:

$$
L_{f 1} \frac{d i}{d t}=V-V_{c}-R_{c}\left(i-i_{g}\right)
$$

where $L_{f 1}$ is the first filter inductance and $R_{c}$ is the damping resistance.

The equation of the filter capacitor is defined as

$$
C \frac{d V_{c}}{d t}=i-i_{g}
$$

where $\mathrm{C}$ is the filter capacitance. 


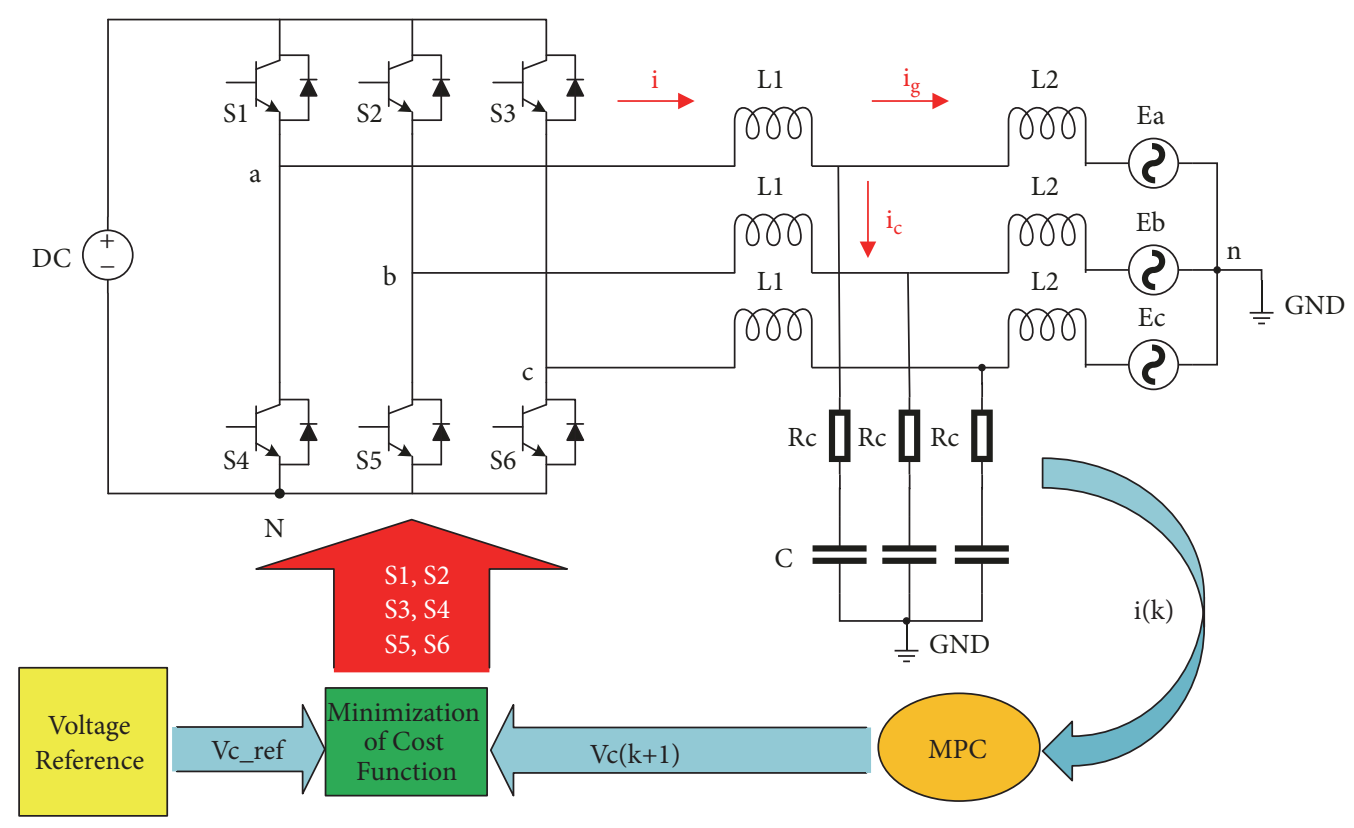

FIGURE 3: Control diagram of a three-phase inverter connected to the grid.

\section{Principle of MPVC}

Model predictive capacitor filter voltage control design and implement consist as the following steps:

(1) Using a discrete-time model to predict the behaviour of current and voltage for the next time step.

(2) Minimizing the cost function to find the best voltage vector $V(k)$.

(3) Determining the duration for the nonzero and zero voltage vector.

The controller design and controller parameters' adjustment will be more difficult whereas an LCL filter is involved at the output of the inverter. So in the applications that include an LCL filter, the capacitor filter voltage is regulated, while the grid current is controlled in L-filter based applications. As the proposed model predictive voltage control scheme is shown in Figure 3, this method uses the discrete-time model for the three-leg inverter and LCL filter to predict the capacitor filter voltage based on prediction of the output current and then selects a switching state based on the minimization of cost function for each sampling time [20,21].

Predictions of the future output current and capacitor filter voltage at the moment of $(\mathrm{k}+1)$ for different values of voltage vector $V_{k}$ will be acquired based on discrete-time equation, respectively, as follows $[7,18,22]$ :

$$
\begin{aligned}
& i(k+1) \\
& =i(k)+\frac{T_{s p}}{L}\left[V(k)-V_{c}(k)-R_{c}\left(i(k)-i_{g}(k)\right)\right] \\
& V_{c}(k+1)=V_{c}\left((k)+\frac{T_{s p}}{C}\left(i(k+1)-i_{g}(k)\right)\right.
\end{aligned}
$$

And now by substituting (12) into (13), the following expression is obtained for the future capacitor filter voltage at $(k+$ 1)th instant.

$$
\begin{aligned}
& V_{c}(k+1)=V_{c}\left((k)+\frac{T_{s p}}{C}\{i(k)\right. \\
& +\frac{T_{s p}}{L}\left[V(k)-V_{c}(k)-R\left(i(k)-i_{g}(k)\right)\right] \\
& \left.-i_{g}(k)\right\}
\end{aligned}
$$

3.1. Minimization of Cost Function. By considering an output LCL filter in this method, a different analysis and more accurate mathematical model is given for controlling the output voltage and consequently a better output voltage quality defined as the control objectives in the cost function. Hence, to select the optimal voltage vector $V(k)$ applied by the inverter, the seven $V_{c}((k+1)$ are compared using a cost function $g$ to find the best voltage vector $V(k)$, which minimizes this function, for selecting and applying at the next sampling instant $[20,21]$.

Therefore, a cost function $g$ will be expressed by measuring the error between the references and the predicted capacitor filter voltage.

$$
\begin{aligned}
g= & \left|\operatorname{Re}\left[V_{c \_r e f}-V_{c}(k+1)\right]\right| \\
& +\left|\operatorname{Im}\left[V_{c_{\lrcorner} \text {ref }}-V_{c}(k+1)\right]\right|
\end{aligned}
$$

where $V_{c}(k+1)$ is predicted from (14) and $V_{c \_r e f}$ is obtained from

$$
V_{c_{-} r e f}=\frac{2}{3}\left(V_{c a_{-} r e f}+a V_{c b_{-} r e f}+a^{2} V_{c c_{-} r e f}\right)
$$


where $V_{c a \_r e f}, V_{c b \_r e f}$, and $V_{c c \_r e f}$ are the reference capacitor filter voltage for phases $a, b$, and $c$, which are generated by sine wave creator with the $120^{\circ}$ phase displacement.

The capacitor filter voltage equals its reference when $g=$ 0 . Therefore, the goal of the cost function is considered to achieve $g$ value close to zero. In other words, this paper is looking for less capacitor filter voltage error to choose the voltage vector and then applied to the next sampling instant $[5,19]$.

3.2. Duty Cycle Determination. In the proposed MPVC, determination of the duration for the nonzero voltage vector is the key to control system. Hence, slopes of the capacitor filter voltage for the nonzero voltage $S_{1}$ vector and the zero voltage vector $S_{0}$ will be calculated easily from (11) $[14,15,23]$.

$$
\begin{aligned}
& s_{1} \\
& =\frac{\left\{i(k)+\left(T_{s p} / L\right)\left[V_{n-z}-V_{c}(k)-R\left(i(k)-i_{g}(k)\right)\right]-i_{g}(k)\right\}}{C} \\
& s_{0}=\frac{\left\{i(k)+\left(T_{s p} / L\right)\left[-V_{c}(k)-R\left(i(k)-i_{g}(k)\right)\right]-i_{g}(k)\right\}}{C}
\end{aligned}
$$

where $V_{n-z}$ is the best voltage vector, which minimizes the cost function.

Thus capacitor filter voltage at the end of the next control cycle will be written as follows:

$$
\begin{aligned}
& V_{c}(k+1)=V_{c}((k) \\
& \quad+\frac{T_{o p t}\left\{i(k)+\left(T_{s p} / L\right)\left[V_{n-z}-V_{c}(k)-R\left(i(k)-i_{g}(k)\right)\right]-i_{g}(k)\right\}+T_{z}\left\{i(k)+\left(T_{s p} / L\right)\left[-V_{c}(k)-R\left(i(k)-i_{g}(k)\right)\right]-i_{g}(k)\right\}}{C} \\
& T_{o p t}+T_{z}=T_{s p} \\
& V_{n-z}+V_{z}=V(k)
\end{aligned}
$$

where $T_{o p t}$ and $T_{z}$ are the optimal duration of the nonzero and zero voltage vectors, respectively.

Now, by replacing (17) and (18) into (19) the capacitor filter voltage at the end of the next control period can be obtained by

$$
V_{c}(k+1)=V_{c}+s_{1} \times T_{o p t}+s_{0} \times\left(T_{s p}-T_{o p t}\right)
$$

The optimal duration of $T_{o p t}$ that minimizes the cost function during a control period satisfies the following condition [8]:

$$
\frac{\partial g}{\partial T_{o p t}}=0
$$

By replacing (22) into (15) and solving (23), the duration of the nonzero vector can be expressed as

$$
T_{o p t}=\frac{\left|V_{c_{-} r e f}-V_{c}(k)-s_{0} \times T_{s p}\right|}{\left|s_{1}-s_{0}\right|}
$$

It is necessary to consider that the value of $T_{o p t}$ can be equaled to zero only if $T_{o p t}$ is less than zero, and $T_{o p t}$ is more than $T_{s p}$; then it will be equaled to $T_{s p}[16]$.

3.3. Implemented Control Flowchart. Flowchart of the proposed MPVC with duty cycle optimization for obtaining the optimal output voltage vector and their optimal durations is illustrated in Figure 4.

\section{Simulation and Experimental Results}

4.1. Simulation Results. To validate the proposed MPVC, a simulation model of a two-level three-phase inverter with output LCL filter connected to the grid has been developed with the parameters as shown in Table 1 by using MATLAB/Simulink under various conditions. The simulated model is built based on the system shown in Figure 5. The simulation analysis is mainly about robustness of the proposed MPVC strategy. Hence, for this purpose, the performance of the proposed strategy will be compared with the conventional scheme.

First of all, by comparison of grid current waveforms for the proposed and conventional methods, it is clear that the proposed MPVC has much less distortion in output current than conventional MPVC and the proposed MPCC methods, and even conventional MPVC has better results as compared to the conventional MPCC. Therefore, it is going to present less current ripples and lower current harmonics as seen in Figure 6.

Then, to proof this stability for the proposed method, the capacitor filter voltage will be explored in simulation. As it is shown in Figure 7, there is a good tracking of capacitor filter voltage to its reference in the proposed method; and even by changing the voltage level, the proposed method tracking the voltage reference is still more accurate and has lower ripples than the conventional. Hence, it could be a reason to have lower current harmonics.

Figures 8 and 9 show a harmonic spectrum analysis at the sampling times $T_{s p}=50 \mu$ s for the grid current and the capacitor filter voltage, respectively. From one point of view, it can be clearly seen the current THDs in the proposed methods which are $1.91 \%$ and $2.54 \%$ for MPVC and MPCC, respectively, much better than the conventional strategies results which are $2.95 \%$ for MPVC and $4.29 \%$ for MPCC. Moreover, the conventional MPVC gets better results as 


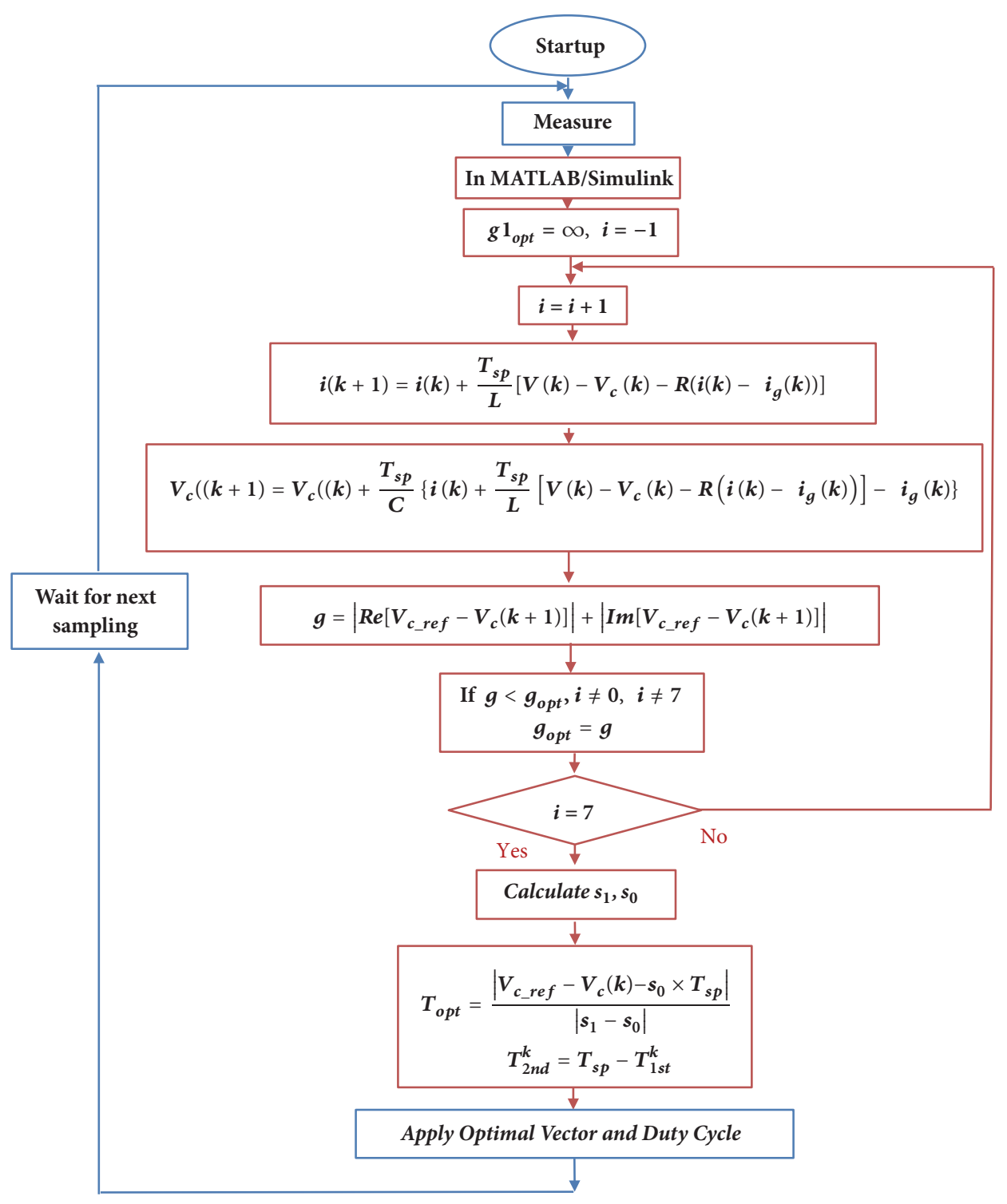

FIGURE 4: Flowchart of the proposed MPVC with duty cycle optimization.

TABLE 1: Parameters used for the simulation and experiment.

\begin{tabular}{lcc}
\hline Variable & System Parameters & Value \\
\hline$V_{d c}$ & DC-Link voltage & $700 \mathrm{~V}$ \\
$e$ & Grid Voltage (RMS) & $220 \mathrm{~V}$ \\
$f$ & Line voltage frequency & $50 \mathrm{~Hz}$ \\
$v_{r e f}$ & Reference voltage peak amplitude & $311 \& 240 \mathrm{~V}$ \\
$L_{2}$ & Filter inductance & $1 \mathrm{mH}$ \\
$L_{1}$ & Filter Inductance & $3 \mathrm{mH}$ \\
$C_{f}$ & Filter Capacitance & $15 \mu \mathrm{F}$ \\
$R_{c}$ & Damping Resistance & $10 \Omega$ \\
$T_{s p}$ & Sampling time & 25 to $100 \mu \mathrm{s}$ \\
\hline
\end{tabular}




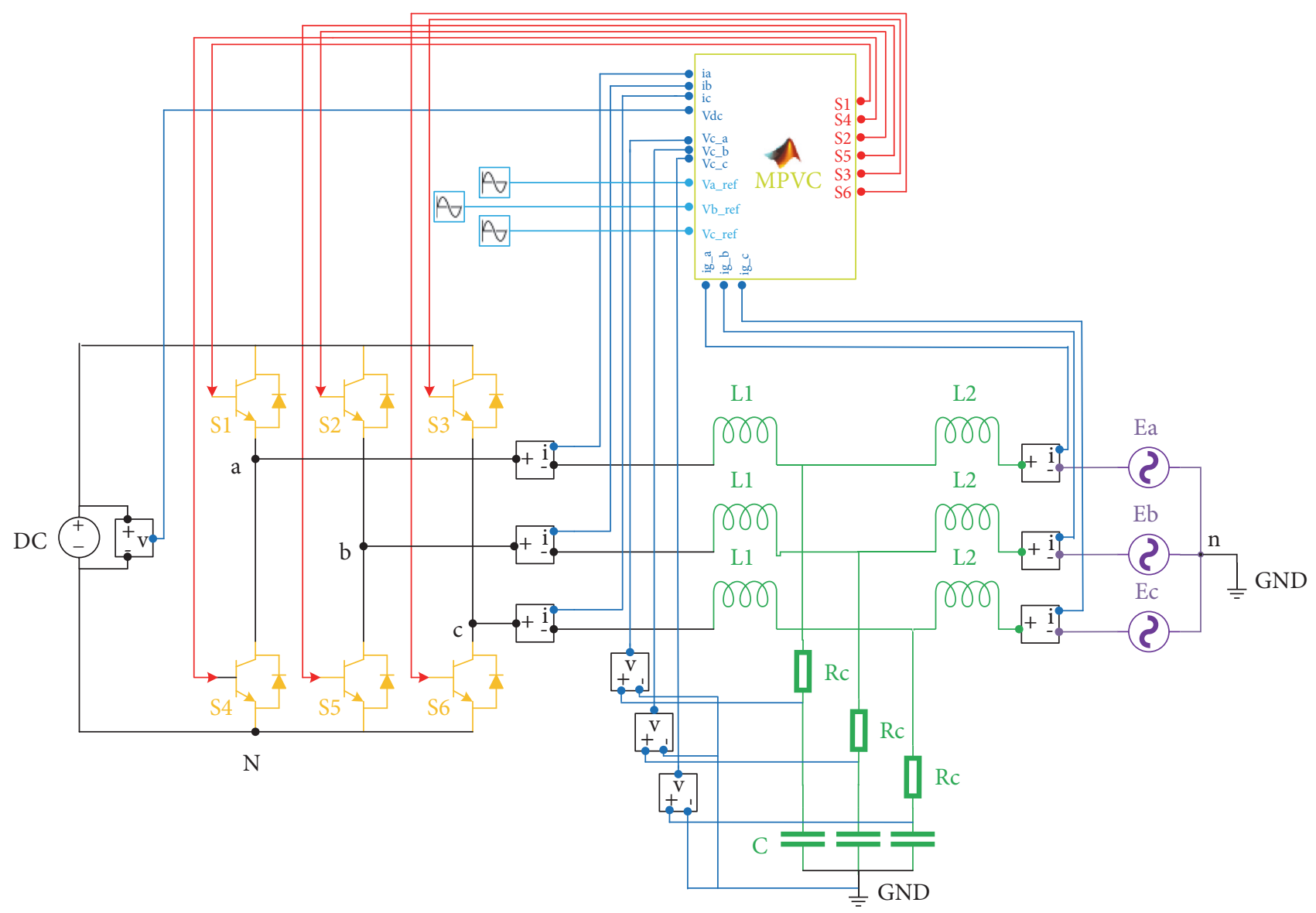

(a)

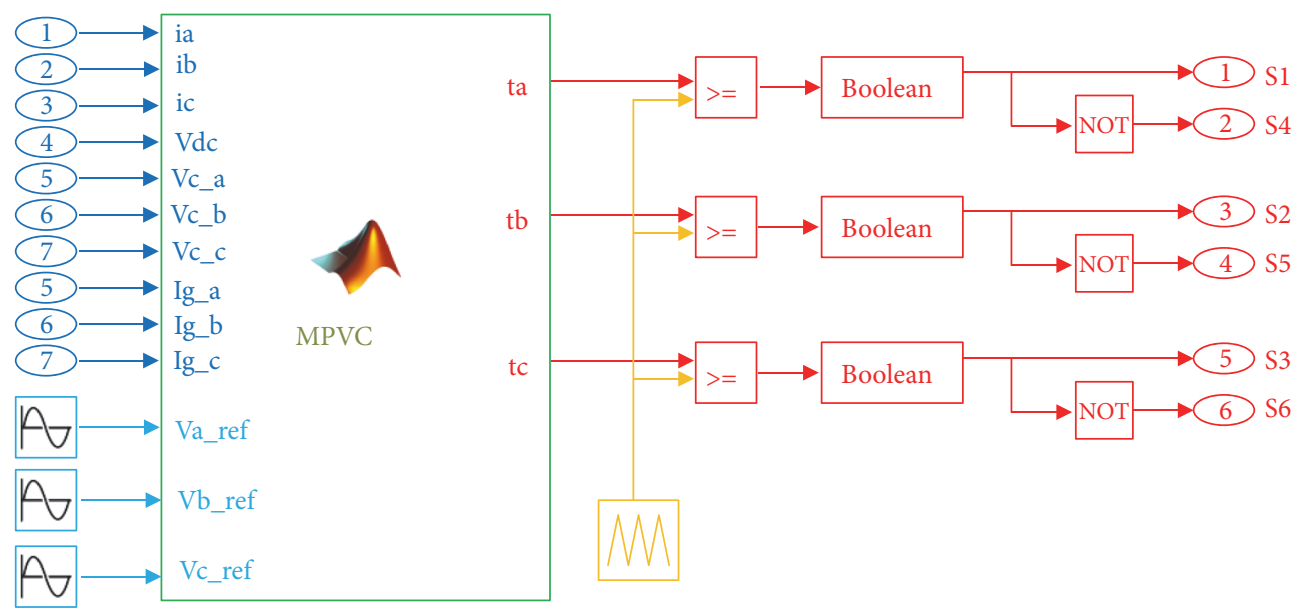

(b)

FIgURE 5: Simulation diagram in MATLAB/Simulink. (a) Proposed MPVC with duty cycle control for a three-phase inverter connected to the grid. (b) Subsystem of the MPVC.

compared to the conventional MPCC, which proves the benefits of controlling the capacitor filter voltage. Therefore, the current waveforms are more closed to sinusoidal, which proves the efficiency of proposed MPVC with optimal duty cycle control. On the other side, comparing the THD of capacitor filter voltage for two methods shows that the proposed MPVC still has a better performance by $4.05 \%$ than conventional by $6.03 \%$. So in the conventional strategy to achieve less THD, the sampling frequency is needed to increase, and increasing the sampling frequency can be a reason for higher hardware expenses. However, in the proposed MPVC this problem is solved by using duty cycle 


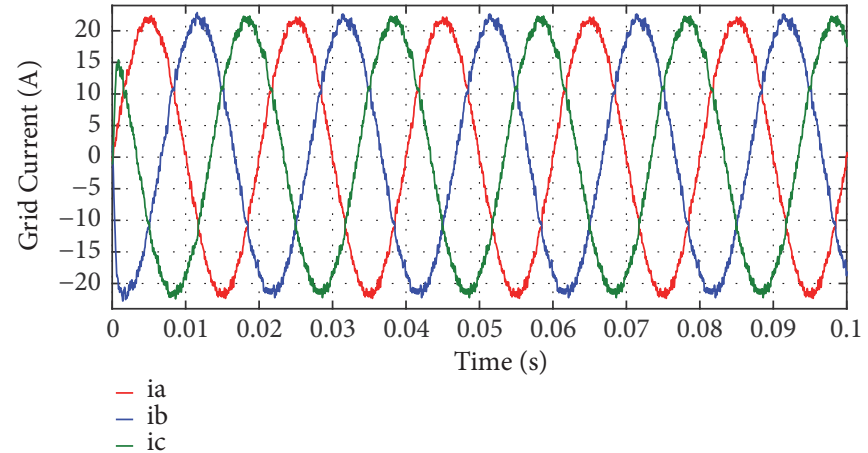

(a)

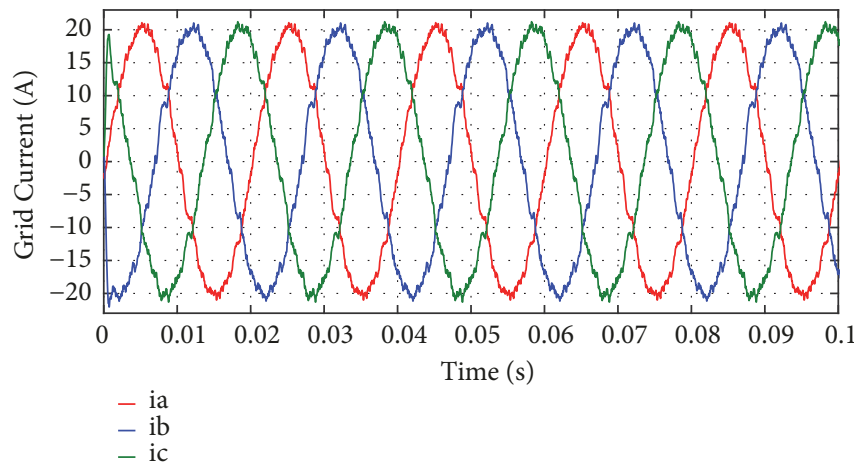

(c)

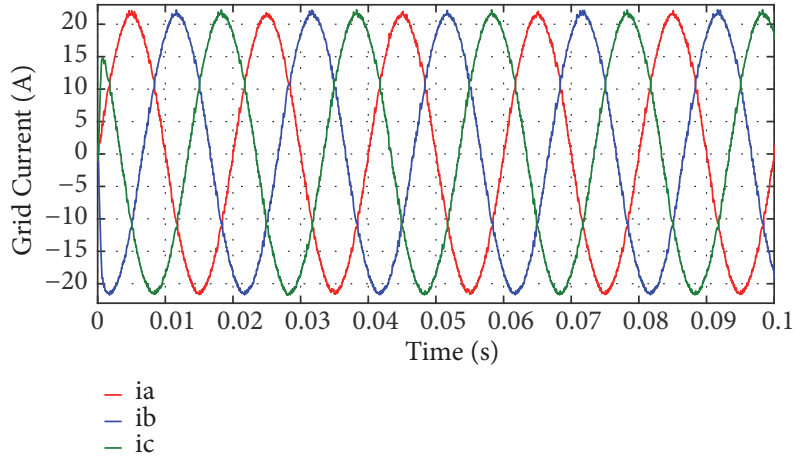

(b)

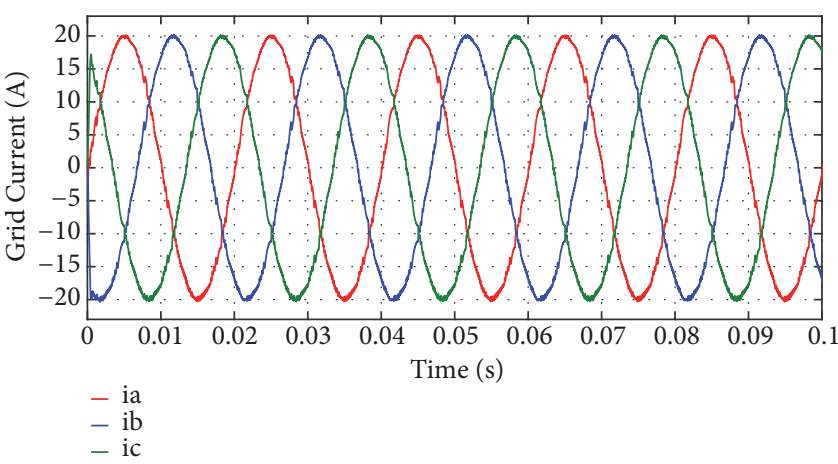

(d)

FIGURE 6: Simulation waveform of three phase grid current at 50 $\mu$ s sampling time for (a) the conventional MPVC, (b) the proposed MPVC, (c) the conventional MPCC, and (d) the proposed MPCC.

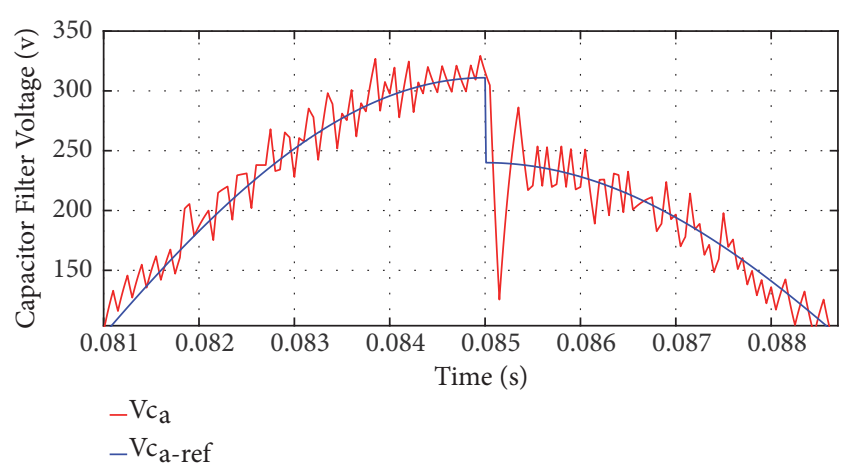

(a)

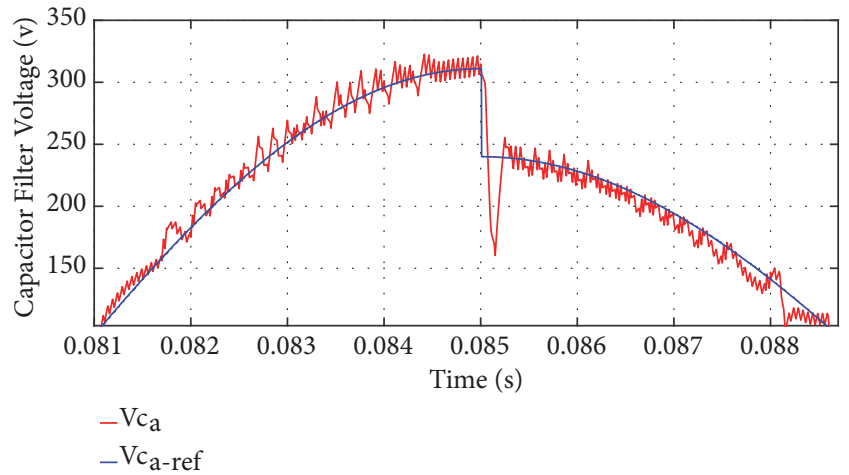

(b)

FiguRE 7: Simulation waveform of capacitor filter voltage (phase a) at the sampling time $T_{s p}=50 \mu$ s for two different voltage levels: (a) the conventional MPVC, (b) the proposed MPVC.

optimization; then this goal is obtained without increasing the sampling time.

Figure 10 shows a bar chart of THD for the grid current and the capacitor filter voltage in different methods with various sampling times and it can prove that the proposed method has significantly lower THD values than the conventional one because of the idea of duty cycle optimization. As shown in Figure 10, the proposed method can set more substantial advantages in systems by a larger sampling frequency.
Figure 11 shows the results for a step change in the amplitude of the reference voltage from $311 \mathrm{~V}$ to $240 \mathrm{~V}$. Therefore, the grid current also will be changed according to the reference voltage step change (see Figure 12). It can be observed that by following the change of the reference voltage, the amplitude of the grid currents will be changed with extremely rapid dynamics while being not affected by this step change. However, as shown in Figure 7, the amplitude of the capacitor filter voltage does not gain its reference in a short time. Overall, by comparing two methods, 


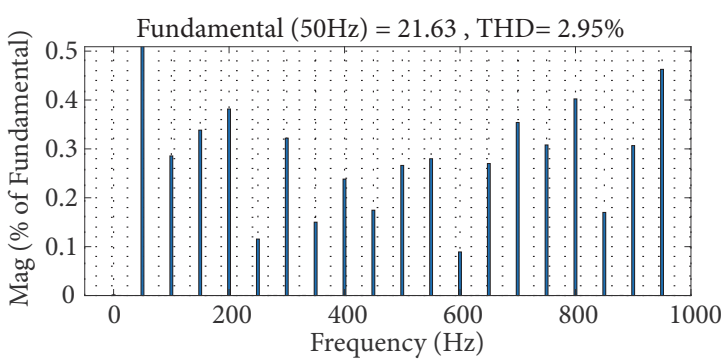

(a)

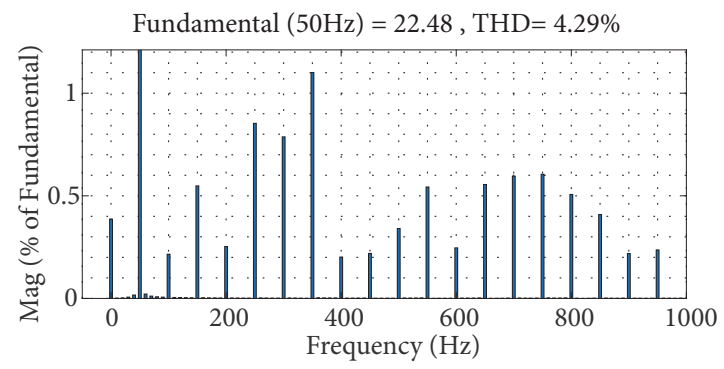

(c)

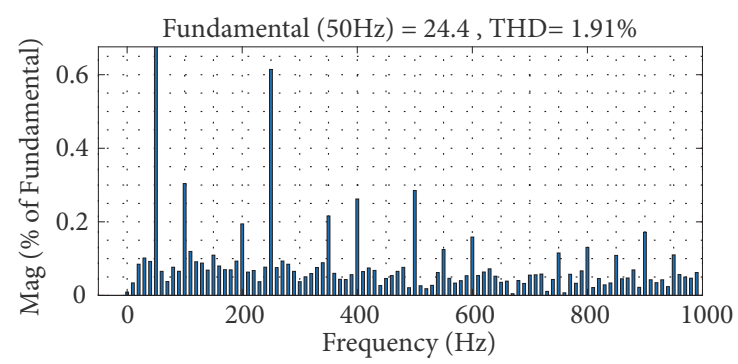

(b)

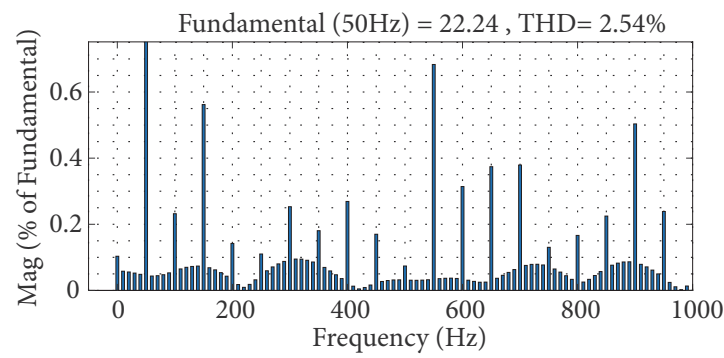

(d)

Figure 8: Total harmonic distortion of grid current at 50 $\mu$ s sampling time for (a) the conventional MPVC, (b) the proposed MPVC, (c) the conventional MPCC, and (d) the proposed MPCC.

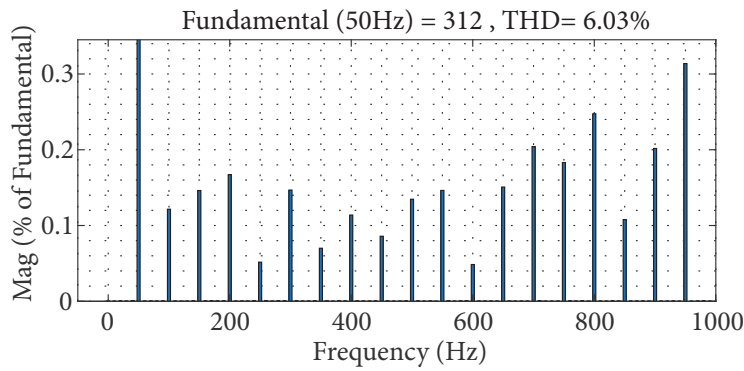

(a)

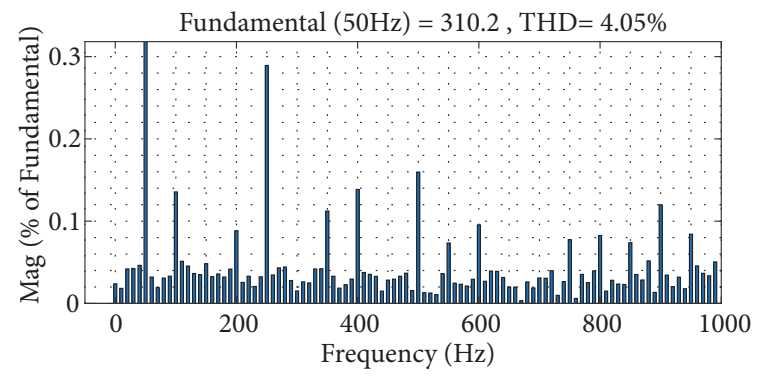

(b)

Figure 9: Total harmonic distortion of capacitor filter voltage at $50 \mu$ s sampling time for (a) the conventional MPVC and (b) the proposed MPVC.

the proposed MPVC has a better dynamic performance than conventional method.

The absolute error will be defined as differences between the reference current and the measured grid current. To reveal the possibilities of the proposed MPVC method, comparison of the absolute reference tracking error for the MPVC and MPCC strategies is presented in Figure 13. Therefore, it is clear that the MPVC strategy is more stable than the proposed MPCC, as it has less absolute reference tracking error compared to the MPCC method.

At last the detailed measurements of THD for the capacitor filter voltage and the grid current are summarized in Table 2 for the MPVC and MPCC methods. Hence, it is clear that the proposed MPVC with duty cycle optimization achieves much better steady-state performance and lower THD as compared to the proposed MPCC
4.2. Experimental Tests. To verify whether simulation model can be realized, an experiment was performed and evaluated as well. Therefore, the proposed MPVC algorithm has been tested on a laboratory prototype system including a threephase inverter connected to the grid. The main system parameters are summarized with the same system parameters used for the simulation (see Table 1). The core of the control hardware is based on A 32-bit floating digital signal processor (DSP) TMS320F28335 where the proposed MPVC algorithm has been coded. And a Fluke 434 power quality analyser is used in the prototype as measuring equipment. The threephase grid-tied inverter prototype was set up according to Figure 14.

As shown in Figure 15, the experimental output current waveform seems slightly worse than the simulation results, but still in the proposed methods, the current waveform is 


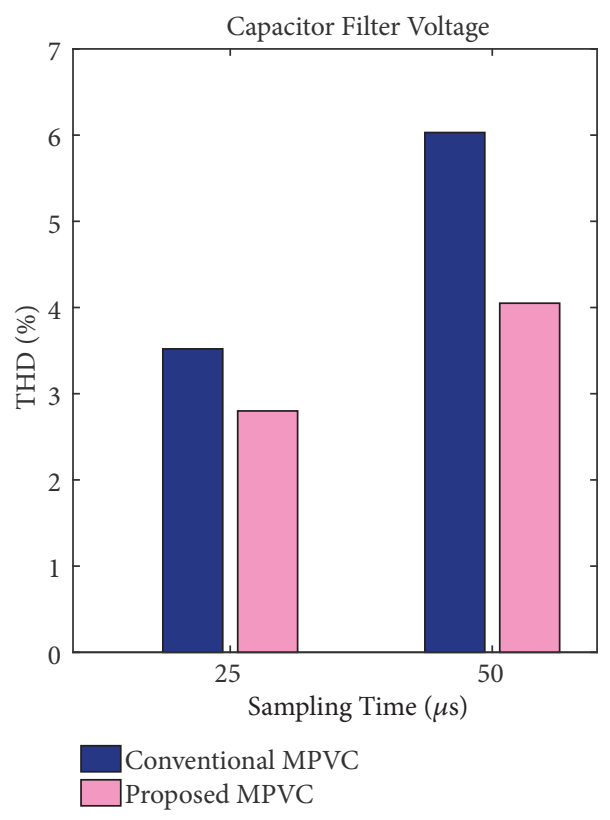

(a)

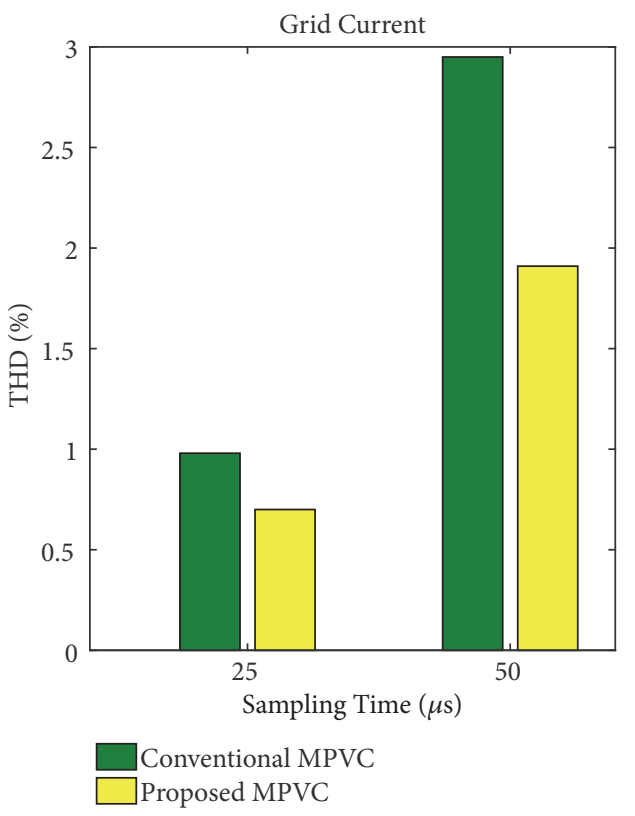

(b)

FIGURE 10: Comparative simulation results of THD for the conventional and proposed MPVC. (a) Capacitor filter voltage. (b) Grid current.

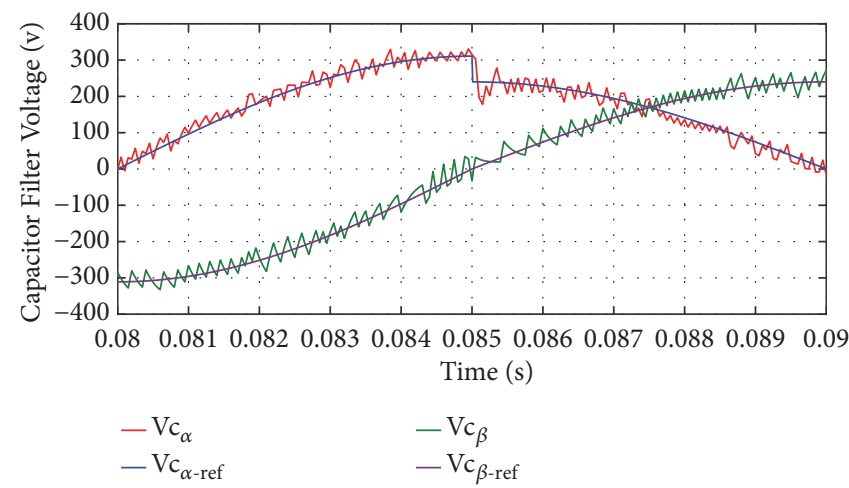

(a)

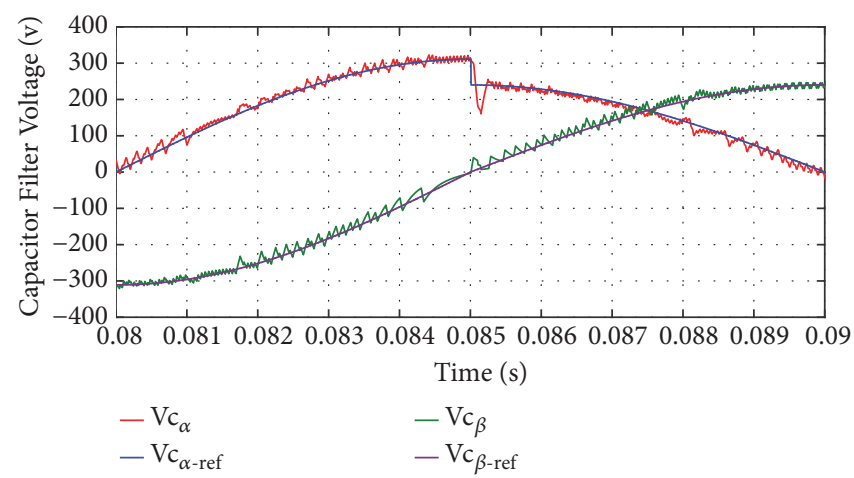

(b)

FIGURE 11: Results of capacitor filter voltage for a step in the amplitude of $V c_{\alpha_{s} r e f}$ and $V c_{\beta_{\triangleleft} \text { ref }}$. (a) The conventional MPVC. (b) The proposed MPVC.

smoother as compared to the conventional methods. To confirm these changes, Figure 16 shows the distorted waveform of the inverter output current THD, where the conventional and the proposed MPVC methods are $7.2 \%$ and $3.1 \%$; and the conventional and proposed MPCC methods are $7.3 \%$ and $3.3 \%$, respectively. Thus, the proposed strategy has much better performance in comparison with the conventional one and along with the voltage controlling gets better results as compared to the current controlling.

\section{Conclusion}

In this paper, a new and simplified control strategy was presented for a three-phase inverter with output LCL filter. The capability of the proposed predictive voltage controller has been simulated in MATLAB/Simulink. Results show that the proposed strategy obtains a better voltage regulation with linear loads as well as nonlinear loads. The cost function in the algorithm of the control strategy checks each of the 7 possible switching states to choose a better switching state that minimizes the errors. The proposed MPVC achieves an improved steady-state performance by using nonzero and zero vector during one control period. In addition, it improves performance by employing predictive output current to predict capacitor filter voltage as well. Hence, the algorithm defines the duration of the nonzero vector based on the principle of capacitor voltage error minimization. Therefore, this idea (duty ratio optimization) is another advantage to get a better steady-state performance. The proposed MPVC method can decrease steady-state voltage errors and reduce grid current ripples without increasing the sampling frequency compared to the Proposed MPCC 


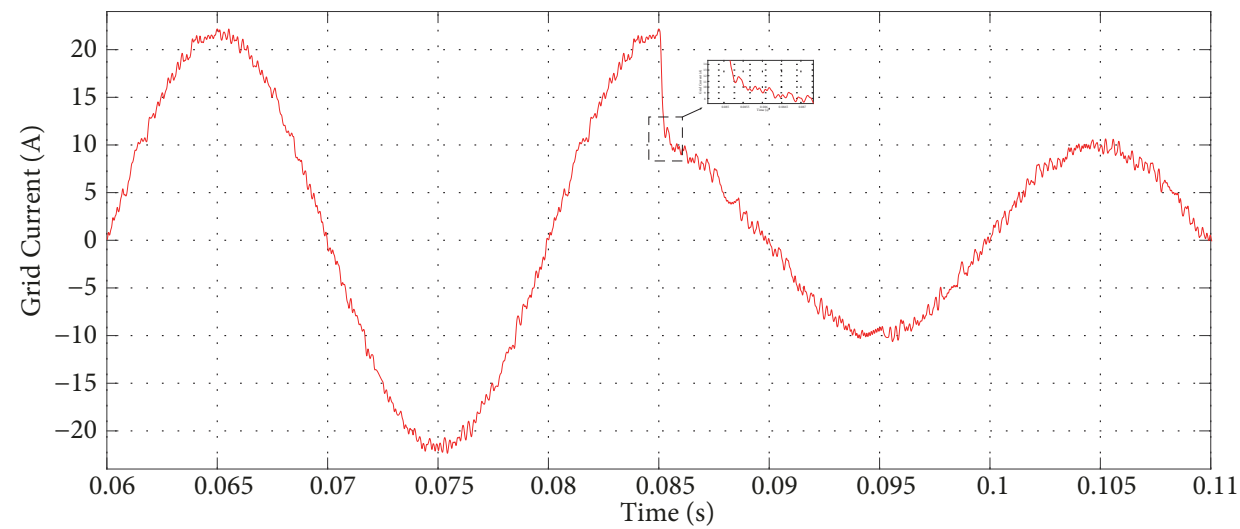

(a)

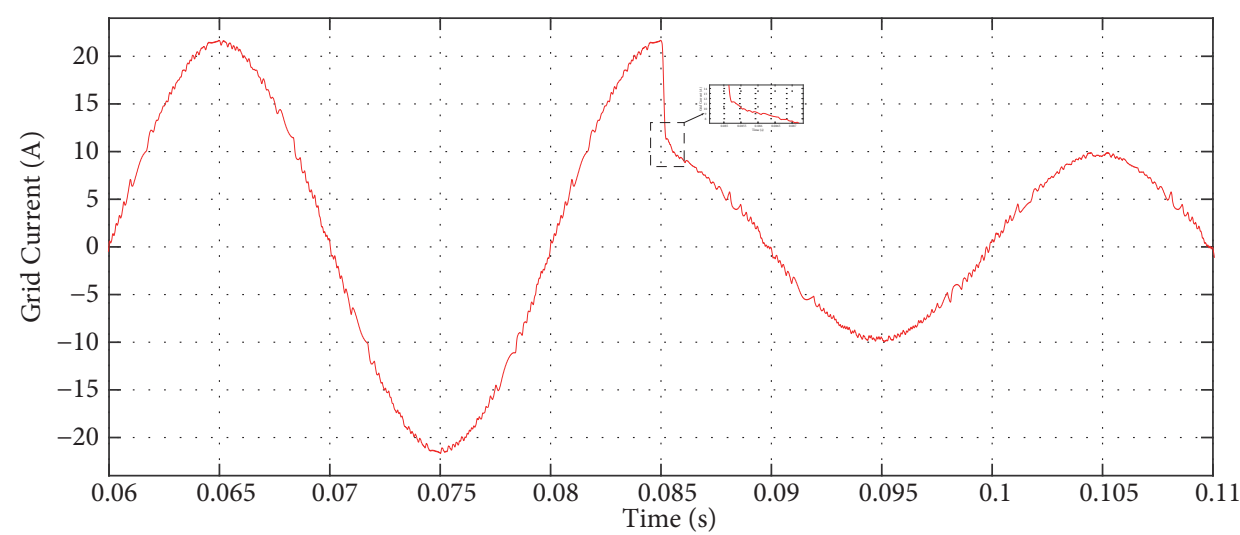

(b)

FIgURE 12: Grid current of phase A for (a) the conventional MPVC and (b) the proposed MPVC.

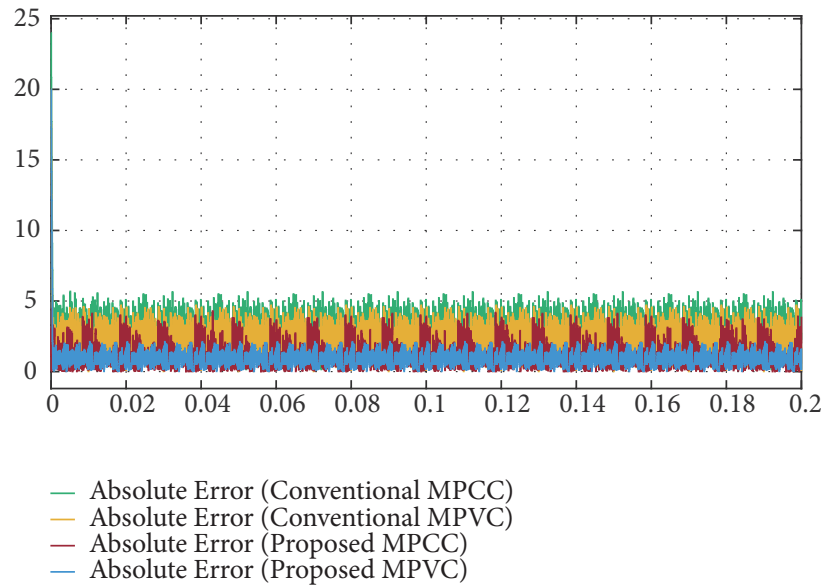

(a)

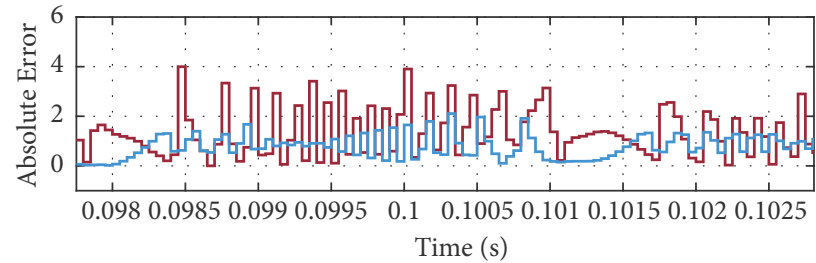

Lower Tolerance

Upper Tolerance

- Absolute Error (Proposed MPCC)

- Absolute Error (Proposed MPVC)

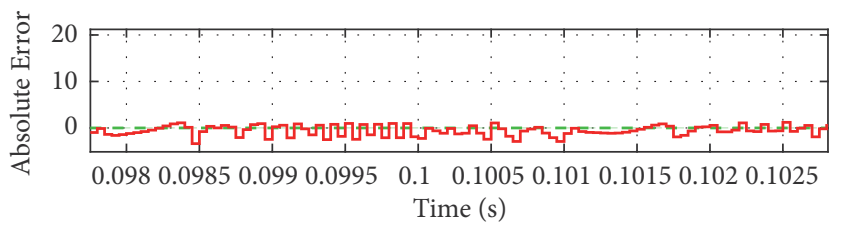

Difference of Baseline from Lower Tolerance

- Difference of Baseline from Upper Tolerance

- Difference

(b)

FIGURE 13: Absolute reference current tracking error. (a) Comparison of the conventional and proposed strategies. (b) Difference between proposed MPCC and MPVC. 
TABLE 2: Comparison of THD for MPVC and MPCC methods.

\begin{tabular}{|c|c|c|c|c|c|c|}
\hline \multirow[b]{3}{*}{$\begin{array}{l}\text { Sampling Time } \\
(\mu \mathrm{s})\end{array}$} & \multicolumn{6}{|c|}{ THD (\%) } \\
\hline & \multicolumn{2}{|c|}{ Conventional MPVC } & \multicolumn{2}{|c|}{ Proposed MPVC } & \multirow{2}{*}{$\begin{array}{c}\text { Conventional } \\
\text { MPCC }\end{array}$} & \multirow{2}{*}{$\begin{array}{c}\begin{array}{c}\text { Proposed } \\
\text { MPCC }\end{array} \\
\text { Grid Current }\end{array}$} \\
\hline & Grid Current & $\begin{array}{c}\text { Capacitor filter } \\
\text { Voltage }\end{array}$ & Grid Current & $\begin{array}{c}\text { Capacitor filter } \\
\text { Voltage }\end{array}$ & & \\
\hline 25 & 0.98 & 3.52 & 0.7 & 2.8 & 3.2 & 1.94 \\
\hline 50 & 2.95 & 6.03 & 1.91 & 4.05 & 4.29 & 2.54 \\
\hline
\end{tabular}

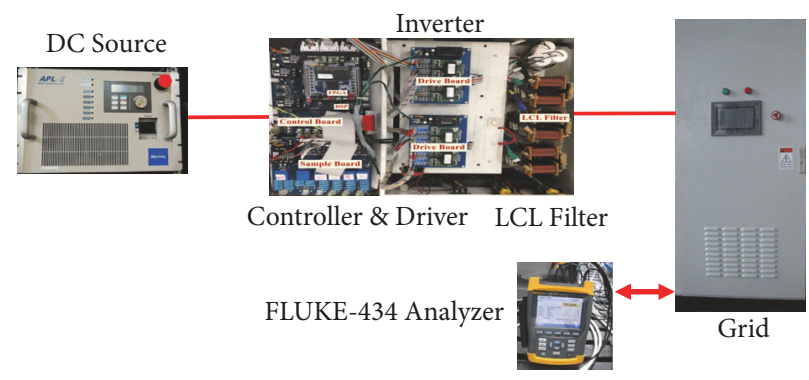

FiguRE 14: Laboratory setup.

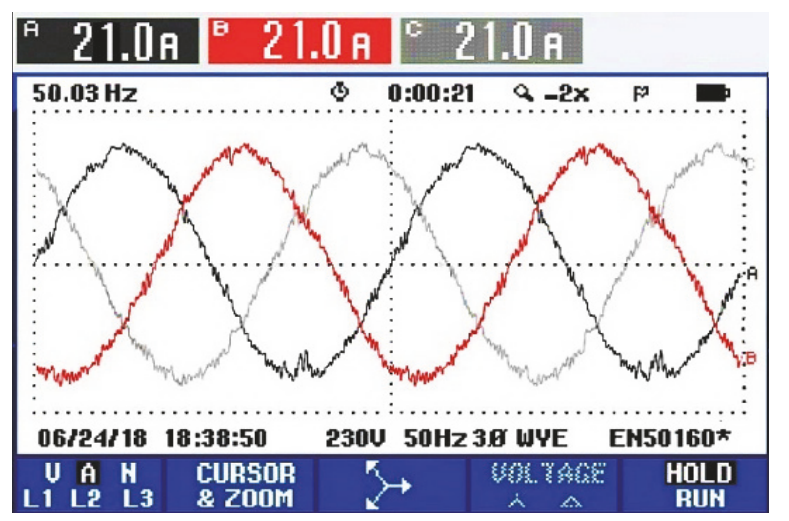

(a)

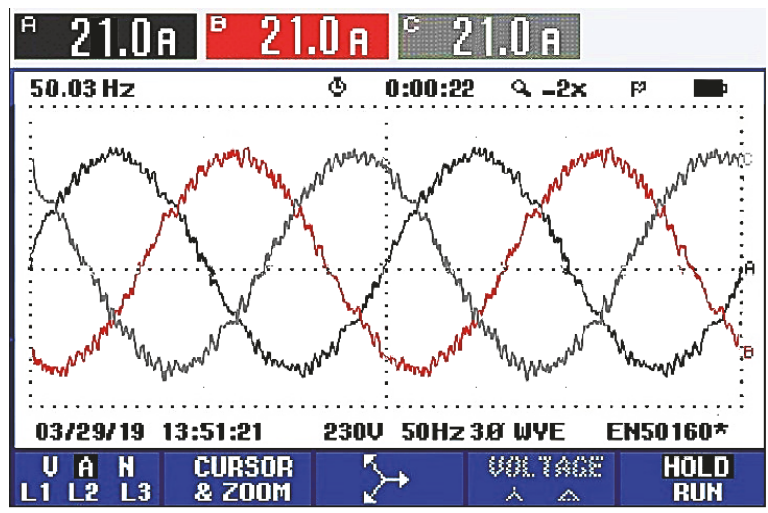

(c)

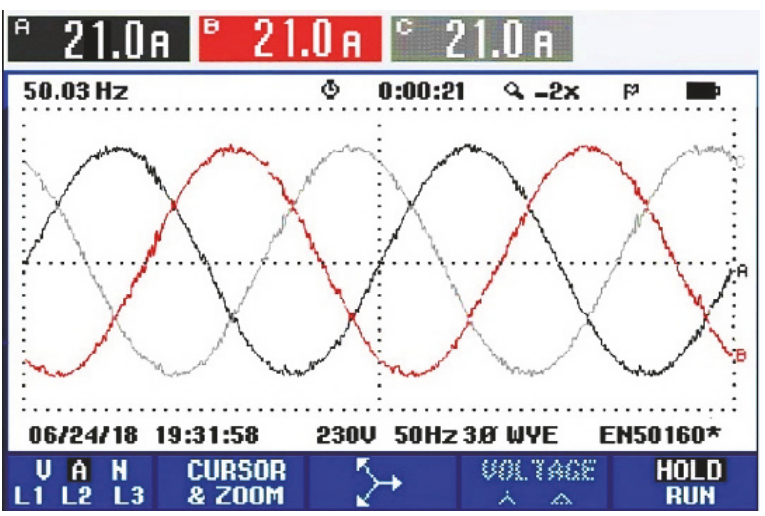

(b)

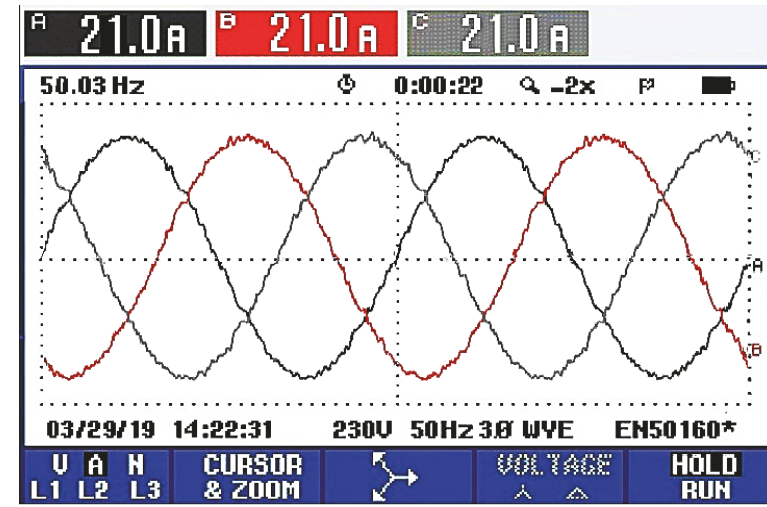

(d)

FIGURE 15: Waveform of three-phase grid current: (a) the Conventional MPVC, (b) the proposed MPVC, (c) the conventional MPCC, and (d) the proposed MPCC. 


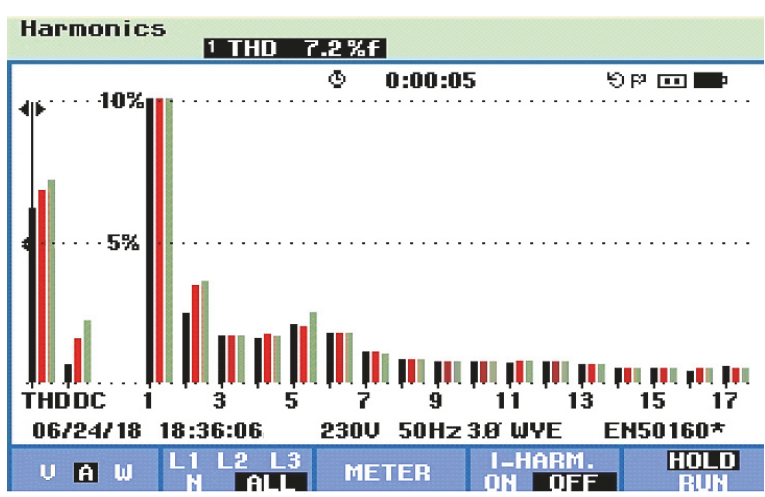

(a)

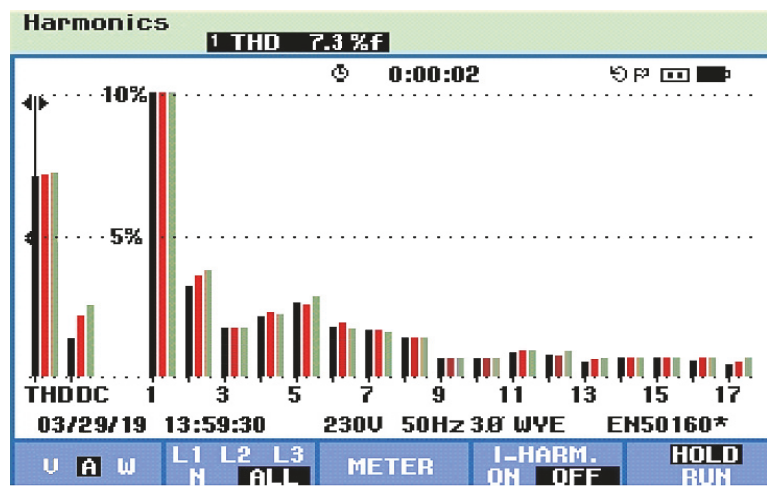

(c)

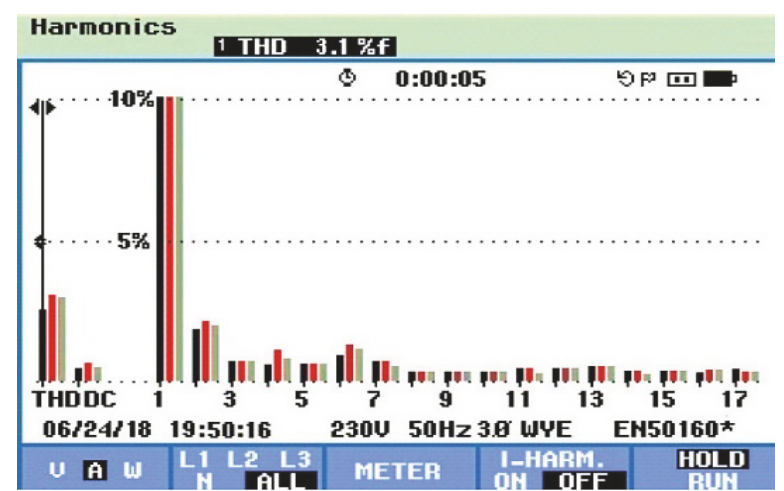

(b)

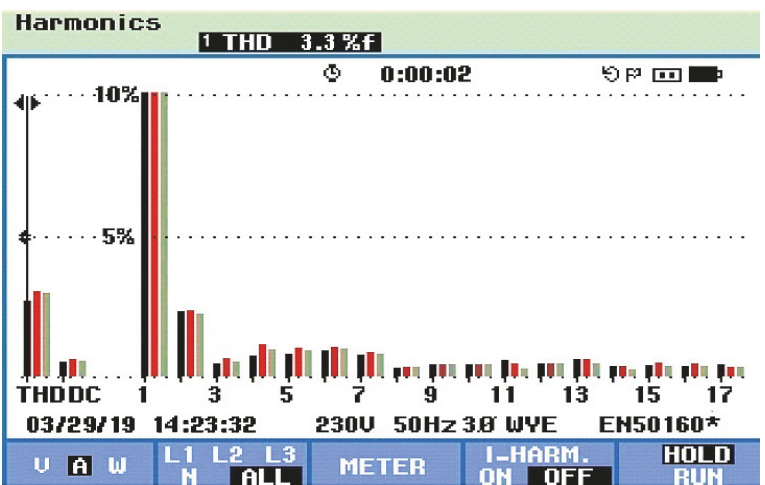

(d)

FIGURE 16: THD of the three-phase grid current: (a) the conventional MPVC, (b) the proposed MPVC, (c) the conventional MPCC, and (d) the proposed MPCC.

strategy. The proposed strategy offers a better reference tracking error with less THD values in the capacitor voltage and grid current as well. From the other point of view, it can be a reason for better system stability and remarkable improvement in the dynamic performance of the inverter by the reference voltage step changing. Hence, the presented simulation and experimental results agree on the efficiency of the proposed MPVC with duty cycle optimization.

\section{Data Availability}

The system analysis data achieved from the MATLAB/ Simulink and experimental test used to support the findings of this study are available from the first author (Shahrouz Ebrahimpanah,shahrooz6485@yahoo.com) upon request.

\section{Conflicts of Interest}

The authors declare that they have no conflicts of interest.

\section{Acknowledgments}

This work was supported by the National Natural Science Foundation of China under contract 61374050, 61673305, 61673306, and the National Key Research and Development Program of China under contract 2017YFB0103001.

\section{References}

[1] X. Xing, C. Zhang, J. He, A. Chen, and Z. Zhang, "Model predictive control for parallel threelevel T-type grid-connected inverters in renewable power generations," IET Renewable Power Generation, vol. 11, no. 11, pp. 1353-1363, 2017.

[2] D. Abbes, A. Martinez, and G. Champenois, "Eco-design optimisation of an autonomous hybrid wind-photovoltaic system with battery storage," IET Renewable Power Generation, vol. 6, no. 5, pp. 358-371, 2012.

[3] C. H. F. Silva, H. M. Henrique, and L. C. Oliveira-Lopes, "Experimental application of predictive controllers," Journal of Control Science and Engineering, vol. 2012, Article ID 159072, 18 pages, 2012.

[4] M. B. Shadmand, X. Li, R. S. Balog, and H. Abu Rub, "Constrained decoupled power predictive controller for a singlephase grid-tied inverter," IET Renewable Power Generation, vol. 11, no. 5, pp. 659-668, 2017.

[5] V. Yaramasu, B. Wu, M. Rivera, and J. Rodriguez, "Enhanced model predictive voltage control of four-leg inverters with switching frequency reduction for standalone power systems," in Proceedings of the 15th International Power Electronics and Motion Control Conference, EPE-PEMC 2012 ECCE Europe, pp. DS2c.6-1-DS2c.6-5, Novi Sad, Serbia, September 2012.

[6] V. Yaramasu, M. Rivera, M. Narimani, B. Wu, and J. Rodriguez, "Model predictive approach for a simple and effective load voltage control of four-leg inverter with an output LC filter," 
IEEE Transactions on Industrial Electronics, vol. 61, no. 10, pp. 5259-5270, 2014.

[7] J. Rodriguez, B. Wu, M. Rivera et al., "Predictive current control of three-phase two-level four-leg inverter," in Proceedings of the 14th International Power Electronics and Motion Control Conference (EPE/PEMC 2010), pp. 106-110, IEEE Press, Ohrid, Macedonia, September 2010.

[8] V. Yaramasu, M. Rivera, M. Narimani, B. Wu, and J. Rodriguez, "High performance operation for a four-leg NPC inverter with two-sample-ahead predictive control strategy," Electric Power Systems Research, vol. 123, pp. 31-39, 2015.

[9] W. Chen, "Improved distributed model predictive control with control planning set," Journal of Control Science and Engineering, vol. 2016, Article ID 8167931, 14 pages, 2016.

[10] G. Du, Z. Liu, F. Du, and J. Li, "Performance improvement of model predictive control using control error compensation for power electronic converters based on the lyapunov function," Journal of Power Electronics, vol. 17, no. 4, pp. 983-990, 2017.

[11] C. Xia, T. Liu, T. Shi, and Z. Song, "A simplified finitecontrol-set model-predictive control for power converters," IEEE Transactions on Industrial Informatics, vol. 10, no. 2, pp. 991-1002, 2014.

[12] P. Cortes, J. Rodriguez, C. Silva, and A. Flores, "Delay compensation in model predictive current control of a three-phase inverter," IEEE Transactions on Industrial Electronics, vol. 59, no. 2, pp. 1323-1325, 2012.

[13] J. Rodríguez, J. Pont, C. A. Silva et al., "Predictive current control of a voltage source inverter," IEEE Transactions on Industrial Electronics, vol. 54, no. 1, pp. 495-503, 2007.

[14] Y. Zhang, W. Xie, Z. Li, and Y. Zhang, "Model predictive direct power control of a PWM rectifier with duty cycle optimization," IEEE Transactions on Power Electronics, vol. 28, no. 11, pp. 53435351, 2013.

[15] Y. Zhang and Y. Peng, "Model predictive current control with optimal duty cycle for three-phase grid-connected AC/DC converters," in Proceedings of the 2014 International Power Electronics and Application Conference and Exposition (PEAC), IEEE PEAC 2014, pp. 837-842, IEEE Press, China, November 2014.

[16] Y. Zhang, Y. Peng, and B. Xia, "Efficient model predictive control with optimal duty cycle for power converters," in Proceedings of the 8th IEEE International Power Electronics and Motion Control Conference, IPEMC-ECCE Asia 2016, pp. 10761083, IEEE Press, China, May 2016.

[17] Y. Zhang, C. Qu, Z. Li, Y. Zhang, and L. Cao, "Direct power control of PWM rectifier with optimal duty ratio under unbalanced network," in Proceedings of the 9th International Conference on Power Electronics - ECCE Asia, ICPE 2015-ECCE Asia, pp. 11161122, Seoul, South Korea, June 2010.

[18] S. Ebrahimpanah, Q. Chen, and L. Zhang, "Model predictive current control with duty cycle optimization for two-level threephase grid-tied inverter with output LCL filter based on forward euler approximation," in Proceedings of the 3rd International Conference on Industrial Informatics - Computing Technology, Intelligent Technology, Industrial Information Integration, ICIICII 2017, pp. 155-158, China, December 2017.

[19] P. Cortés, G. Ortiz, J. I. Yuz et al., "Model predictive control of an inverter with output LC filter for UPS applications," IEEE Transactions on Industrial Electronics, vol. 56, no. 6, pp. 18751883, 2009.

[20] E. Zangeneh Bighash, S. M. Sadeghzadeh, E. Ebrahimzadeh, and F. Blaabjerg, "High quality model predictive control for single phase grid-connected photovoltaic inverters," Electric Power Systems Research, vol. 158, pp. 115-125, 2018.

[21] E. Z. Bighash, S. M. Sadeghzadeh, E. Ebrahimzadeh, and F. Blaabjerg, "Robust MPC-based current controller against grid impedance variations for single-phase grid-connected inverters," ISA Transactions, vol. 84, pp. 154-163, 2019.

[22] J. Rodriguez and P. Cortes, Predictive Control of Power Converters and Electrical Drives, Wiley-IEEE Press, 2012.

[23] P. Mercorelli, "A multilevel inverter bridge control structure with energy storage using model predictive control for flat systems," Journal of Engineering, vol. 2013, Article ID 750190, 15 pages, 2013. 


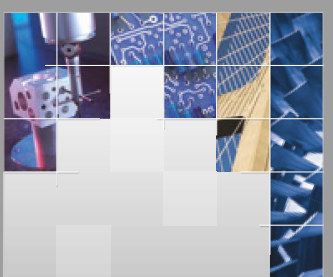

\section{Enfincering}
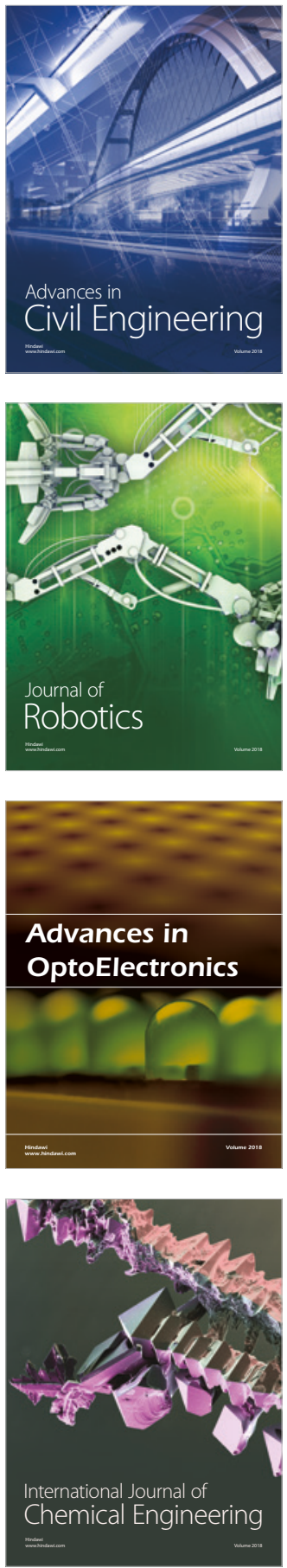

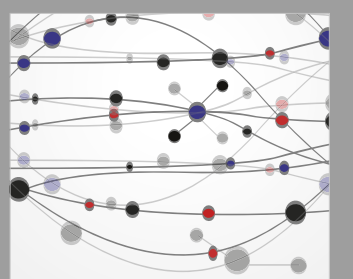

\section{Rotating \\ Machinery}

The Scientific World Journal

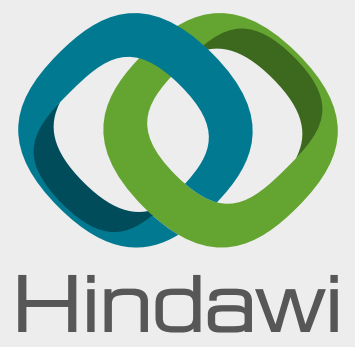

Submit your manuscripts at

www.hindawi.com
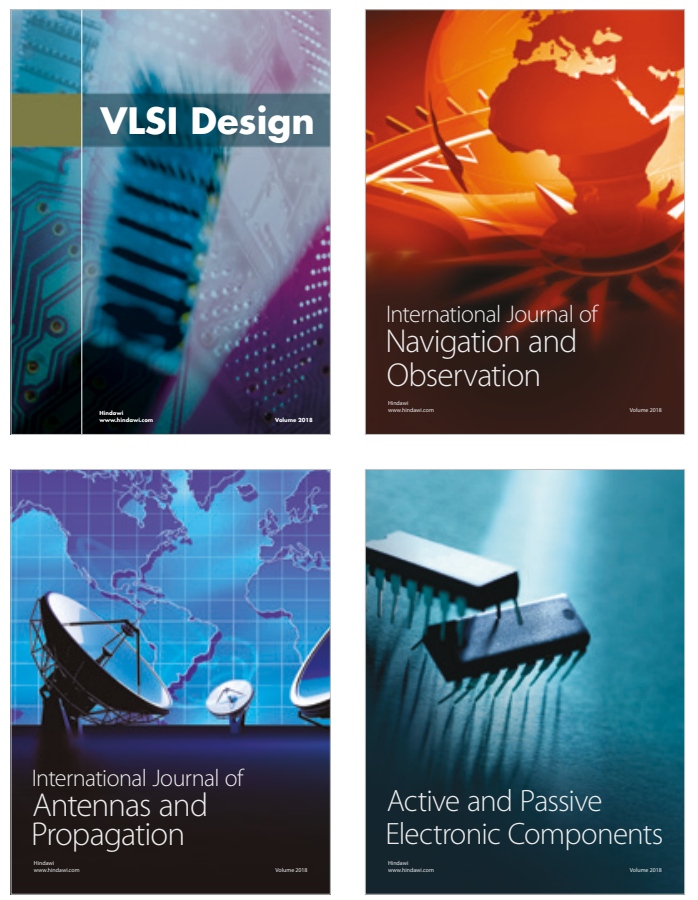
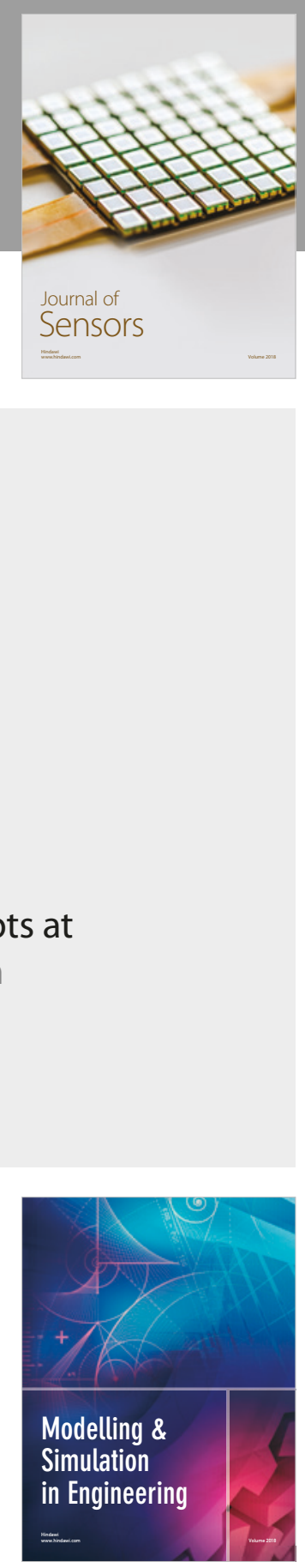

\section{Advances \\ Multimedia}
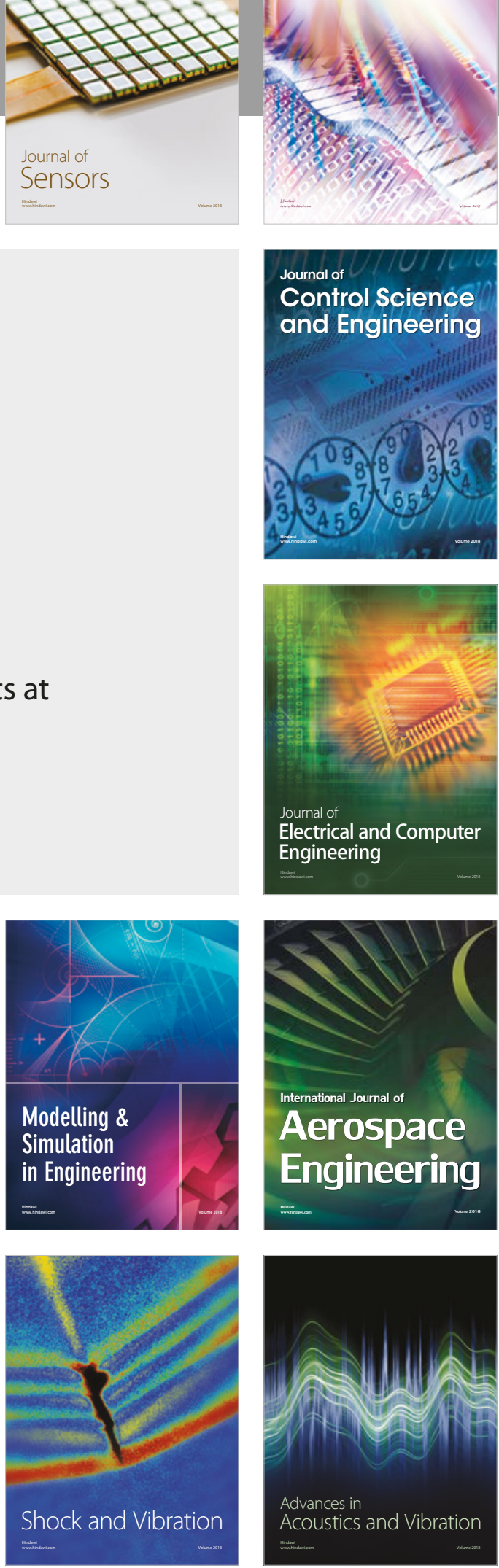